Check for updates

Cite this: Chem. Sci., 2019, 10, 8566

๑ All publication charges for this article have been paid for by the Royal Society of Chemistry

Received 4th July 2019

Accepted 26th July 2019

DOI: $10.1039 / \mathrm{c} 9 \mathrm{sc03315g}$

rsc.li/chemical-science

\section{Reversal of reaction type selectivity by Lewis acid coordination: the ortho photocycloaddition of 1- and 2-naphthaldehyde $\uparrow$}

\author{
Simone Stegbauer, Noah Jeremias, Christian Jandl and Thorsten Bach (D) *
}

The value of a specific substrate class for synthetic applications is greatly enhanced if different types of reactions can be performed selectively upon a judicious choice of reaction conditions. In the present study it was shown that the typical photochemical behaviour of naphthaldehydes is completely altered in the presence of Lewis acids. Without Lewis acids, reactions at the carbonyl group are exclusively observed while Lewis acids facilitate a visible light-mediated cycloaddition at the arene core providing access to products of aromatic $\mathrm{C}-\mathrm{H}$ functionalization via cyclobutane intermediates.

\section{Introduction}

Upon direct excitation, 1-naphthaldehyde (1) and 2-naphthaldehyde (2) undergo photochemical transformations at the aldehyde carbonyl group. Like for many other aromatic aldehydes, the typical reaction products are oxetanes (PaternòBüchi reaction ${ }^{1,2}$ ), ${ }^{3}$ alcohols (photoreduction) ${ }^{4}$ or carbonyl addition products (photoaddition). ${ }^{5}$ The reaction of 1-naphthaldehyde (1) in 2,3-dihydrofuran for example has been reported to deliver oxetane 3 in a yield of $55 \%$ (Scheme 1). ${ }^{3 d}$ The reactivity pattern is determined by the $n \pi^{*}$ character of the

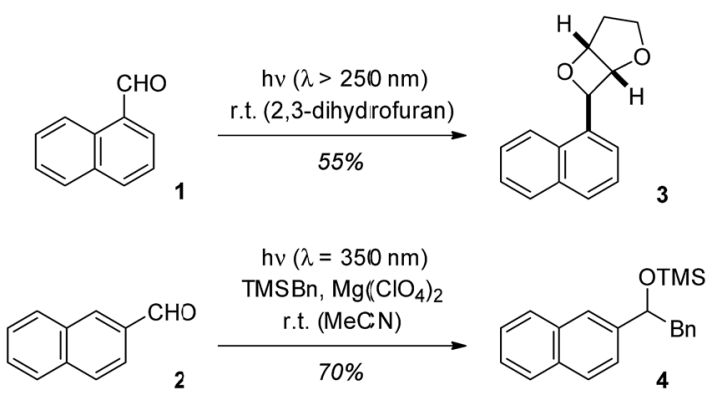

Scheme 1 Paternò-Büchi reaction of 1-naphthaldehyde (1) to oxetane 3 (top) and $\mathrm{Mg}\left(\mathrm{ClO}_{4}\right)_{2}$-mediated photoaddition of benzyltrimethylsilane to 2-naphthaldehyde (2).

Department Chemie and Catalysis Research Center (CRC), Technische Universität München, 85747 Garching, Germany. E-mail: thorsten.bach@ch.tum.de; Fax: +49 89 28913315; Tel: +498928913330

$\uparrow$ Electronic supplementary information (ESI) available: Synthetic procedures and full characterization for all starting materials and products $(\mathbf{5 - 1 0}, \mathbf{1 3 - 1 5}, \mathbf{1 8})$, spectroscopic data, low temperature NMR spectra. CCDC 1937926. For ESI and crystallographic data in CIF or other electronic format see DOI: 10.1039/c9sc03315g reactive excited states (singlet or triplet) ${ }^{6}$ or it is due to electron transfer pathways which generate a radical anion by reduction of the carbonyl group.

In recent work, the influence of Lewis acids on photochemical reactions has been studied with a focus on enantioselective transformations. ${ }^{7}$ However, it was also noted that the Lewis acid modifies other selectivity parameters. ${ }^{8}$ We hypothesized that by Lewis acid coordination to the carbonyl group of naphthaldehydes their typical photochemical behaviour may change because the lowest excited states are of $\pi \pi^{*}$ character. This speculation was supported by previous experiments on photoinduced electron transfer (PET) reactions of silanes to naphthaldehydes. ${ }^{9}$ In the absence of a Lewis acid the aldehydes are not sufficiently reactive to undergo a PET with silanes such as benzyltrimethylsilane (TMSBn). The addition of magnesium perchlorate (4 eq. relative to 2 ) allows for the desired transformation and product 4 was obtained in the reaction of 2naphthaldehyde (2) and TMSBn (2 eq.).

In the context of these reactions, Fukuzumi and co-workers studied the photophysical properties of Lewis acid $\left[\mathrm{Mg}\left(\mathrm{ClO}_{4}\right)_{2}\right.$ or $\mathrm{Sc}(\mathrm{OTf})_{3}$ ] complexes with naphthaldehydes $\mathbf{1}$ and $\mathbf{2}$ in great detail. ${ }^{9 b}$ While the enhanced reactivity in the reaction with silanes was ascribed to the higher redox potential of the photoexcited Lewis acid complex, it was also concluded that "the $\pi, \pi^{*}$ excited state becomes the lowest excited state in the $\mathrm{Mg}\left(\mathrm{ClO}_{4}\right)_{2}$ complex as compared with the lowest $\mathrm{n}, \pi^{*}$ triplet excited state in the uncomplexed carbonyl compound".

In the present study, we have compared the photochemical reactivity of 1- and 2-naphthaldehyde towards a typical olefin component (2,3-dimethyl-2-butene) in the absence and in the presence of catalytic amounts of strong Lewis acids. The Lewis acids induced a complete reversal of the type selectivity from carbonyl reactions in the absence of a Lewis acid to reactions at the $\mathrm{C} 1 / \mathrm{C} 2$ double bond of the aromatic core. To the best of our knowledge, a complete type selectivity reversal in the 
photochemistry of aldehydes has not yet been reported. Previous studies in photochemistry have mainly focussed on the choice of irradiation wavelength ${ }^{10}$ or the addition of a triplet sensitizer. One of the most notable type selectivity changes is observed with $\beta, \gamma$-unsaturated enones which undergo an oxadi$\pi$-methane rearrangement in the presence and a 1,3-acyl shift in the absence of a triplet sensitizer. ${ }^{11}$

\section{Results and discussion}

Although 1- and 2-naphthaldehyde had been previously shown to undergo Paternò-Büchi and photocycloaddition reactions with olefins ${ }^{3}$ we closely examined the yet unreported reaction with 2,3-dimethylbutene in order to rule out any involvement of the aromatic $\pi$ system. Upon irradiation at $\lambda=366 \mathrm{~nm}$ product formation was observed and three major products could be isolated and identified for both aldehydes (Fig. 1). 1-Naphthaldehyde (1) delivered oxetane 5a and the two carbonyl addition products $6 \mathbf{a}$ and $7 \mathbf{a}$ in a combined yield of $63 \%$. 2Naphthaldehyde (2) reacted similarly and furnished oxetane $\mathbf{5 b}$ and the alcohols $\mathbf{6 b}$ and $7 \mathbf{b}$ in a combined yield of $79 \%$. The reactions were notoriously slow and proceeded only with an acceptable conversion if performed in the olefin as the solvent.

There was no photochemical reaction of $\mathbf{1}$ and $\mathbf{2}$ upon irradiation at a longer wavelength $(\lambda \geq 400 \mathrm{~nm})$. This observation is in line with the fact that the two naphthaldehydes are colourless with no absorption bands in the visible part of the spectrum. The spectrum of 1-naphthaldehyde (1) is depicted in Fig. 2 (for the spectrum of 2 , see the ESI $\dagger$ ) that also displays the spectral changes upon gradual addition of $\mathrm{EtAlCl}_{2}$ as the Lewis acid. Isosbestic points at $255 \mathrm{~nm}, 288 \mathrm{~nm}$, and $340 \mathrm{~nm}$ indicate that there are only two UV active species present in solution. The absorption of the Lewis acid complex stretches into the visible region and the solution of the complex is yellow-coloured. Likewise 2-naphthaldehyde (2) showed a less pronounced but clearly identifiable absorption maximum at $\lambda=398 \mathrm{~nm}$.

Based on its UV/Vis spectra it was attempted to photochemically convert 1-naphthaldehyde (1) and 2,3-dimethylbutene in the presence of Lewis acids. At $\lambda=405 \mathrm{~nm}$ there was a Lewis acid catalysed reaction with $\mathrm{EtAlCl}_{2}$ and $\mathrm{AlBr}_{3}$ showing similar activity. The cleanest reaction was recorded with $25 \mathrm{~mol} \% \mathrm{AlBr}_{3}$ at $-78{ }^{\circ} \mathrm{C}$ in dichloromethane solution (Scheme 2). In none of these reactions was there an indication for the formation of carbonyl addition products 5a-7a. Surprisingly, the obtained product was aldehyde $\mathbf{8}$ with a rearranged carbon skeleton. Deuterium labelling experiments revealed that the
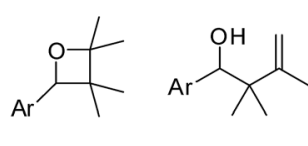

5a $35 \%$

6a $13 \%$

6b $23 \%$

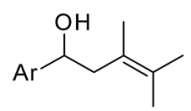

7a $15 \%$

7b $21 \%$

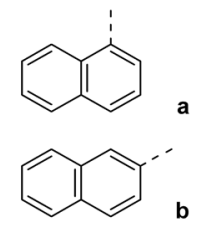

Fig. 1 Products 5-7 obtained by irradiation ( $\lambda=366 \mathrm{~nm}$ ) of 1-naphthaldehyde (1) and 2-naphthaldehyde (2) in a solution of excess (100 eq.) 2,3-dimethyl-2-butene ( $t=20 \mathrm{~h}$ ).

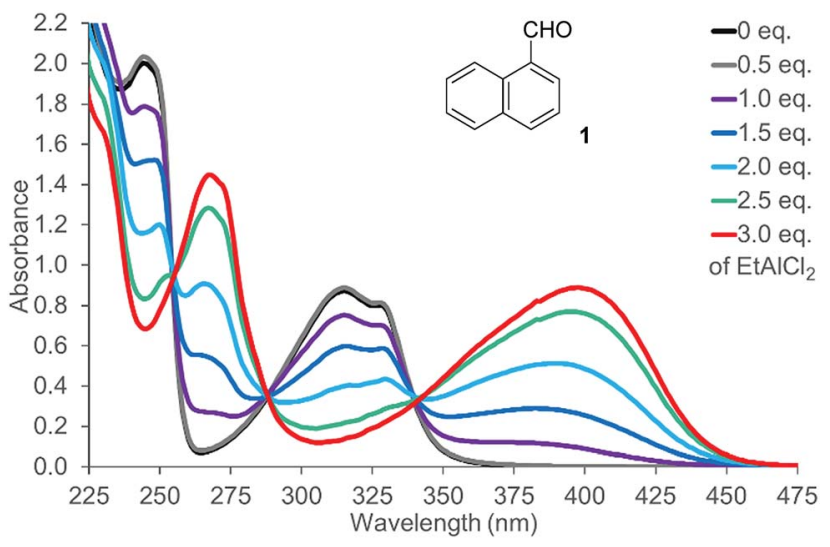

Fig. 2 UV/Vis spectrum of 1 -naphthaldehyde (1) $(c=1.0 \mathrm{mM}$ in $\mathrm{CH}_{2} \mathrm{Cl}_{2}$ ) in the presence of variable equivalents (eq.) of $\mathrm{EtAlCl}_{2}$.

aldehyde proton remains at its position and that the proton at $\mathrm{C} 2$ migrates to $\mathrm{C} 1$ in the course of the reaction. Final proof for the structure was obtained upon reduction of aldehyde $\mathbf{8}$ to alcohol 9 which in turned delivered crystals suitable for single crystal X-ray crystallography.

Since we speculated that aldehyde 8 was derived from an ortho $[2+2]$ photocycloaddition ${ }^{12-14}$ to the naphthalene $\mathrm{C} 1 / \mathrm{C} 2$ bond, cyclobutane $\mathbf{1 0}$ was prepared by an independent route (see ESI $\dagger$ ) and subjected to Lewis acidic conditions (Scheme 3). The formation of aldehyde $\mathbf{8}$ supported our hypothesis and suggests a reaction pathway that commences with Lewis acid coordination to the aldehyde carbonyl group of $\mathbf{1 0}$. The reaction cascade is subsequently initiated by a 1,2-shift to the cationic centre $^{15,16}$ generating benzylic cation 11. An intramolecular hydride shift delivers cation $\mathbf{1 2}$ which eventually undergoes ring opening to the final product.

Once known from independent synthesis, ${ }^{17}$ minor amounts of cyclobutane $\mathbf{1 0}$ were also identified and isolated from the product mixture of some Lewis acid catalysed reactions lending further evidence towards its temporary existence in the formation of aldehyde 8 .

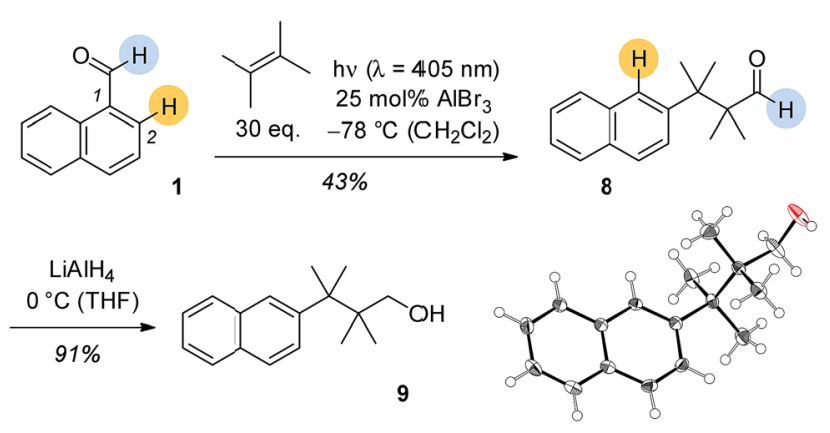

Scheme $2 \mathrm{AlBr}_{3}$-catalysed photochemical reaction of 1-naphthaldehyde (1) and 2,3-dimethyl-2-butene and consecutive reaction of aldehyde 8 to alcohol 9 the constitution of which was established by single crystal $X$-ray crystallography. The marked positions indicate the positions of hydrogen atoms before and after the reaction as determined by deuterium labelling. 

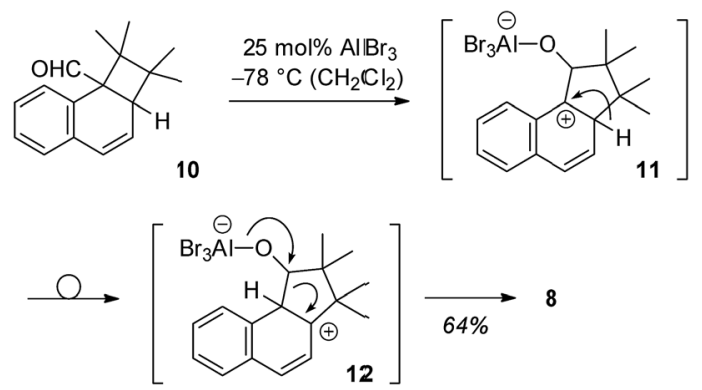

Scheme 3 Suggested reaction course for the formation of aldehyde 8 from ortho photocycloaddition product 10 via intermediates 11 and 12 .

In the case of 2-naphthaldehyde (2), the cyclobutane reaction product was stable and could be isolated. A low Lewis acid loading of either EtAlCl${ }_{2}$ or $\mathrm{AlBr}_{3}$ was sufficient to alter the type selectivity of the photochemical reaction with 2,3-dimethylbutene (Scheme 4). As for 1-naphthaldehyde (1) there was no reaction observed at the aldehyde carbonyl atom and products $\mathbf{5 b}-\mathbf{7 b}$ were not detected in the Lewis acid catalysed reactions. The optimal irradiation source turned out to be a light emitting diode (LED) with an emission maximum at $\lambda=457 \mathrm{~nm}$ (Scheme 4). When the photocycloaddition was performed with $5 \mathrm{~mol} \%$ of $\mathrm{AlBr}_{3}$ in dichloromethane at $-78{ }^{\circ} \mathrm{C} 56 \%$ of product 13 were isolated. With other Lewis acids $\left[\mathrm{BF}_{3}, \mathrm{AlCl}_{3}, \mathrm{Sc}(\mathrm{OTf})_{3}\right]$ there was no reaction under these conditions.

In the reaction with $\mathrm{AlBr}_{3}$ as catalyst a side product was obtained in varying amounts and there were hints that the product was a consecutive product of cyclobutane 13. If the reaction mixture was warmed to $0{ }^{\circ} \mathrm{C}$ after complete photochemical conversion, a further transformation to this product continued which was complete after another 12 hours. The product was identified as alcohol 14 which could be isolated in $74 \%$ yield (Scheme 5 ). The reaction cascade thus offers access to a formal $[3+2]$ cycloaddition product of 2-naphthaldehyde with $\mathrm{C}-\mathrm{C}$ bond formation at the aldehyde carbon atom and at carbon atom $\mathrm{C} 1$.

Despite the fact that the synthetic scope of the ortho photocycloaddition was not in the focus of our current experiments we performed a related formal $[3+2]$ cycloaddition sequence with 2-naphthaldehyde (2) and cyclopentene. After the photocycloaddition/rearrangement cascade $(\lambda=457 \mathrm{~nm}$, $5 \mathrm{~mol} \% \mathrm{AlBr}_{3}, \mathrm{CH}_{2} \mathrm{Cl}_{2}$ ) the expected alcohol could not be isolated in pure form. It was therefore oxidised (Dess-Martin

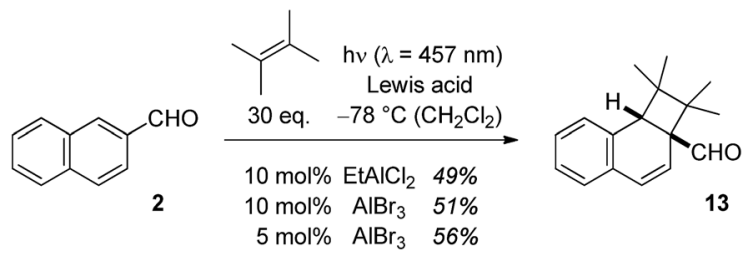

Scheme 4 Intermolecular Lewis acid catalysed ortho photocycloaddition of 2-naphthaldehyde (2) and 2,3-dimethylbutene to cyclobutane 13
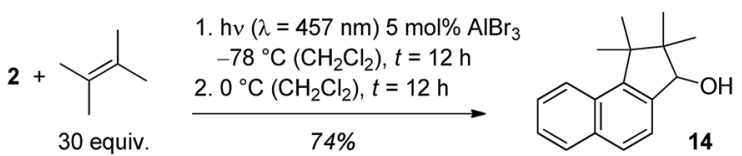

Scheme 5 Optimised conditions for the generation of secondary alcohol 14 by a sequence of $\mathrm{AlBr}_{3}$-catalysed ortho photocycloaddition and rearrangement.

periodinane) to the respective ketone 15 (Fig. 3) which was isolated in an overall yield of $41 \%$ as a single diastereoisomer.

Some preliminary mechanistic experiments ${ }^{\mathbf{1 8}}$ were performed to shed light on the underlying principles of the observed type selectivity reversal. NMR spectra of 2-naphthaldehyde (2) were recorded at $-60{ }^{\circ} \mathrm{C}$ in $\mathrm{CD}_{2} \mathrm{Cl}_{2}$ solution (see the $\mathrm{ESI} \dagger$ for details). Upon addition of $\mathrm{EtAlCl}_{2}(1.1 \mathrm{eq}$.) as Lewis acid there were marked changes ${ }^{\mathbf{1 9}}$ in the NMR shift data which are in full agreement with a coordination of the Lewis acid to the oxygen atom of the carbonyl group. Most notable are the shift changes to lower field for the ${ }^{13} \mathrm{C}$ NMR signals of the carbonyl carbon atom and the carbon atom C1 (Fig. 3). In the ${ }^{1} \mathrm{H}$ NMR spectrum the shielding of the aldehyde proton is most prominent. Together with the UV/Vis spectra (isosbestic point) it seems reasonable to assume that upon addition of Lewis acid a 1 : 1 complex 16 is formed. Attempts to detect this species by luminescence were successful and luminescence spectra could be obtained for both aldehydes $\mathbf{1}$ and $\mathbf{2}$ in the presence of $\mathrm{EtAlCl}_{2}$ (3 eq.) as the Lewis acid in dichloromethane solution. The lifetimes of the luminescent state as determined by time-dependent spectra are below $10 \mu \mathrm{s}$ (detection limit). Given the fact that the emission was observed in solution and given the short lifetime of the luminescent state it appears reasonable to assume that the luminescence is due to emission from the singlet state $S_{1}$ (fluorescence). A delayed luminescence (phosphorescence) could be detected neither in solution nor in a matrix. The fluorescence maxima of the $\mathrm{EtAlCl}_{2}$ complexes were determined to be at $\lambda=468 \mathrm{~nm}$ for $1\left(\lambda_{\text {exc }}=400 \mathrm{~nm}\right)$ and at $\lambda=$ $478 \mathrm{~nm}$ for 2 ( $\lambda_{\text {exc }}=390 \mathrm{~nm}$, Fig. 4$)$.

The emission behaviour of the $\mathrm{EtAlCl}_{2}$ complexes is in stark contrast to the uncomplexed naphthaldehydes which are nonfluorescent in solution but show a strong phosphorescence in a dichloromethane matrix at $77 \mathrm{~K}$ (see the ESI $\dagger$ for more details). Our results are in agreement with previous work of Fukuzumi et al. (vide supra) who had reported for the complexes

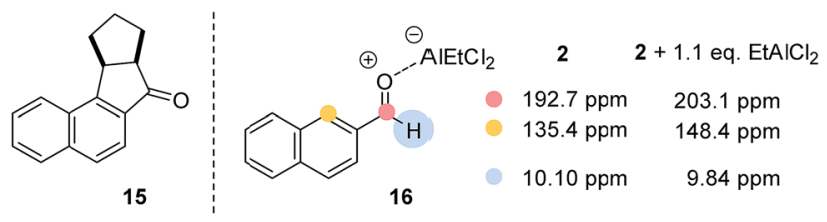

Fig. 3 Structure of the photocycloaddition/rearrangement cascade product 15 (left) and selected NMR shift changes (right) in the Lewis acid complex 16 derived from 2-naphthaldehyde (2) and $\mathrm{EtAlCl}_{2}$ $\left(-60{ }^{\circ} \mathrm{C}, \mathrm{CD}_{2} \mathrm{Cl}_{2}\right)$. 

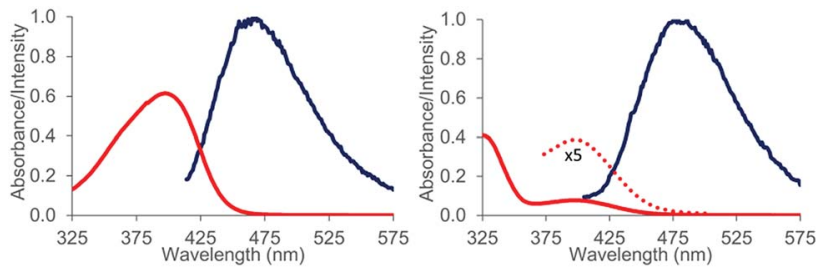

Fig. 4 Normalized absorption and emission spectra as measured for a $\mathrm{CH}_{2} \mathrm{Cl}_{2}$ solution $(0.1 \mathrm{mM})$ of 1-naphthaldehyde (1, left) and 2naphthaldehyde (2, right) in the presence of three equivalents $\mathrm{EtAlCl}$. For clarity only the region between $\lambda=325-575 \mathrm{~nm}$ is displayed and the weak long wavelength absorption obtained for complex 16 ( $\left.2 \cdot \mathrm{AlEtCl}_{2}\right)$ is also expanded by a factor of five (dotted line).

of $\mathrm{Mg}\left(\mathrm{ClO}_{4}\right)_{2}$ and naphthaldehydes $\mathbf{1}$ and 2 a fluorescence in acetonitrile solution with emission maxima at $\lambda=437 \mathrm{~nm}$ and at $\lambda=440 \mathrm{~nm} .{ }^{9 b}$ With $\mathrm{Sc}(\mathrm{OTf})_{3}$ the emission maxima were redshifted to $\lambda=487 \mathrm{~nm}$ and $\lambda=510 \mathrm{~nm}$. In the Fukuzumi study, the fluorescence was quenched upon addition of silanes and products of a PET were obtained ( $c f$. Scheme 1). Surprisingly, in our case, the fluorescence of the naphthaldehyde-EtAlCl${ }_{2}$ complexes was not quenched upon addition of up to 1000 equivalents of 2,3-dimethylbutene. The fluorescence intensity remained identical and there was no change in shape of the fluorescence signal. The result makes it unlikely that the fluorescent states are involved in the observed ortho photocycloaddition. Further evidence that the photocycloaddition does not occur from a singlet state intermediate was obtained from the reaction of 3-hexene (17) with 2-naphthaldehyde (2). The reaction was not stereospecific as both $(E)-17$ and $(Z)-17$ delivered mainly a single product 18 . The reaction time was kept identical (12 hours) and starting material was recovered in both experiments (20\% and 38\%). The yields given in Scheme 6 are not corrected for conversion. When calculated relative to conversion the yield for $\mathbf{1 8}$ was $78 \%$ from $(E)-\mathbf{1 7}$ and $63 \%$ from (Z)-17.

Based on NOESY data for 18 and for the alcohol obtained from 18 by reduction $\left(\mathrm{LiAlH}_{4}\right.$ in THF, 88\% yield, see ESI $\dagger$ for further details), the relative configuration of the two ethyl groups within the cyclobutane ring is trans. Formation of this product from $(Z)-\mathbf{1 7}$ requires the involvement of an intermediate in which free rotation is possible, potentially a triplet 1,4diradical. ${ }^{20}$

Despite this circumstantial evidence, any conclusions regarding the mechanism of the Lewis acid catalysed ortho photocycloaddition reactions are premature at this point in time. When the UV/Vis spectra of 1- and 2-naphthaldehyde were

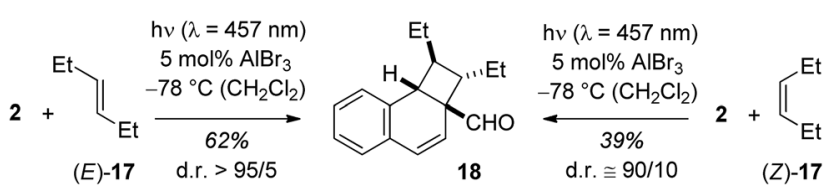

Scheme 6 Stereoconvergent reaction course in the Lewis acid catalysed ortho photocycloaddition of 2-naphthaldehyde (2) and 3-hexene (17). recorded in the presence of a large ( $>3$ eq.) excess of $\mathrm{EtAlCl}_{2}$ (see $\mathrm{ESI} \dagger$ ) they indicated the formation of new species which could potentially also be photochemically active. It is well established that a minor component can be responsible for the reactivity in a catalytic reaction. ${ }^{21}$ The exact assignment of these species needs to be performed and it will also be required to learn more about the reactivity features of the $1: 1$ Lewis acid complexes. The sheer number of various $\pi \pi^{*}$ transition accessible to naphthaldehydes and other aromatic aldehydes complicates the analysis which is much more facile for $\alpha, \beta$-unsaturated carbonyl compounds where apart from the $n \pi *$ transition only a single $\pi \pi^{*}$ transition is responsible for the photochemical reactivity.

\section{Conclusion}

In summary, we have found that naphthaldehydes change their photochemical reactivity pattern dramatically in the presence of EtAlCl$_{2}$ or $\mathrm{AlBr}_{3}$ as Lewis acids. The site of reactivity is shifted from the carbonyl group to the $\mathrm{C} 1 / \mathrm{C} 2$ arene double bond where an initial ortho photocycloaddition with olefins occurs. Consecutive Lewis acid promoted reactions lead to an opening of the cyclobutane ring and to the formation of a C2-alkylated naphthalene in the case of 1-naphthaldehyde (1) and to a formal [3 + 2] cycloaddition product for 2-naphthaldehyde (2). Both reaction pathways create selectively $\mathrm{C}-\mathrm{C}$ bonds at the naphthalene skeleton at the expense of existing $\mathrm{C}-\mathrm{H}$ bonds. In combination with the facile execution of the reaction which requires only catalytic amounts (5-25 mol\%) of the Lewis acid and visible light as energy source $(\lambda=405$ or $457 \mathrm{~nm})$ this feature should make the reactions a valuable supplement to the portfolio of $\mathrm{C}-\mathrm{C}$ bond formation reactions at the naphthalene core.

\section{Conflicts of interest}

There are no conflicts to declare.

\section{Acknowledgements}

Financial support by the European Research Council under the European Union's Horizon 2020 research and innovation programme (grant agreement No. 665951 - ELICOS) and by the Fonds der Chemischen Industrie ( $\mathrm{PhD}$ fellowship to $\mathrm{S}$. S.) is gratefully acknowledged. We thank Dr J. D. Jolliffe for his help with crystal structure analysis and Dr T. S. Chung for the fluorescence measurements.

\section{Notes and references}

1 (a) E. Paternò and G. Chieffi, Gazz. Chim. Ital., 1909, 39, 341; (b) G. Büchi, C. G. Inman and E. S. Lipinsky, J. Am. Chem. Soc., 1954, 76, 4327.

2 For reviews on the Paternò-Büchi reaction: (a) M. D'Auria, Photochem. Photobiol. Sci., 2019, DOI: 10.1039/c9pp00148d; (b) M. Abe, in Handbook of Synthetic Photochemistry, ed. A. Albini and M. Fagnoni, Wiley-VCH, Weinheim, 2009, p. 
217; (c) A. G. Griesbeck and S. Bondock, in CRC Handbook of Organic Photochemistry and Photobiology, ed. W. Horspool and F. Lenci, CRC Press, Boca Raton, 2nd edn, 2004, pp. 60-1; (d) T. Bach, Synthesis, 1998, 683.

3 (a) N. C. Yang, Pure Appl. Chem., 1964, 9, 591; (b) N. C. Yang, M. Nussim, M. J. Jorgenson and S. Murov, Tetrahedron Lett., 1964, 3657; (c) N. C. Yang, M. Kimura and W. Eisenhardt, J. Am. Chem. Soc., 1973, 95, 5058; (d) A. G. Griesbeck, H. Mauder, K. Peters, E.-M. Peters and H. G. von Schnering, Chem. Ber., 1991, 124, 407; (e) M. Abe, M. Ikeda, Y. Shirodai and M. Nojima, Tetrahedron Lett., 1996, 37, 5901; ( $f$ ) M. Abe, M. Ikeda and M. Nojima, J. Chem. Soc., Perkin Trans. 1, 1998, 3261; (g) A. G. Griesbeck, S. Bondock and J. Lex, J. Org. Chem., 2003, 68, 9899.

4 (a) J. Khan and S. G. Cohen, J. Org. Chem., 1991, 56, 938; (b) S. Kohtani, E. Yoshioka, K. Saito, A. Kudo and H. Miyabe, Catal. Commun., 2010, 11, 1049; (c) D. W. Manley, L. Buzzetti, A. MacKessack-Leitch and J. C. Walton, Molecules, 2014, 19, 15324.

5 (a) A. Takuwa, H. Tagawa, H. Iwamoto, O. Soga and K. Maruyama, Chem. Lett., 1987, 1091; (b) S. V. Kessar, A. K. S. Mankotia, J. C. Scaiano, M. Barra, J. Gebicki and K. Huben, J. Am. Chem. Soc., 1996, 118, 4361; (c) S. S. Kim, Y. J. Mah and A. R. Kim, Tetrahedron Lett., 2001, 42, 8315; (d) S. S. Kim, J. A. Chang and Y. J. Mah, J. Photosci., 2002, 9, 5; (e) J. Sun, X. Peng and H. Guo, Tetrahedron Lett., 2015, $56,797$.

6 (a) N. C. Yang, S. L. Murov and T.-C. Shieh, Chem. Phys. Lett., 1969, 3, 6; (b) D. W. Boldridge, B. L. Justus and G. W. Scott, J. Chem. Phys., 1984, 80, 3179; (c) A. M. J. van Eijk, G. B. Ekelmans, W. Klinkenberg, A. H. Huizer and C. A. G. O. Varma, J. Chem. Soc., Faraday Trans., 1990, 86, 2083.

7 (a) R. Brimioulle and T. Bach, Science, 2013, 342, 840; (b) J. Du, K. L. Skubi, D. M. Schultz and T. P. Yoon, Science, 2014, 344, 392; (c) T. R. Blum, Z. D. Miller, D. M. Bates, I. A. Guzei and T. P. Yoon, Science, 2016, 354, 1391; (d) X. Huang, T. R. Quinn, K. Harms, R. D. Webster, L. Zhang, O. Wiest and E. Meggers, J. Am. Chem. Soc., 2017, 139, 9120; (e) S. Poplata and T. Bach, J. Am. Chem. Soc., 2018, 140, 3228; ( $f$ ) S. Poplata, A. Bauer, G. Storch and T. Bach, Chem.-Eur. J., 2019, 25, 8135.

8 Review: C. Brenninger, J. D. Jolliffe and T. Bach, Angew. Chem., Int. Ed., 2018, 57, 14338.

9 (a) S. Fukuzumi, T. Okamoto and J. Otera, J. Am. Chem. Soc., 1994, 116, 5503; (b) S. Fukuzumi, N. Satoh, T. Okamoto, K. Yasui, T. Suenobu, Y. Seko, M. Fujitsuka and O. Ito, J. Am. Chem. Soc., 2001, 123, 7756.

10 For reviews on the wavelength selectivity of photochemical reactions: (a) S. Protti, D. Ravelli and M. Fagnoni, Photochem. Photobiol. Sci., DOI: 10.1039/c8pp00512e; (b) N. J. Turro, V. Ramamurthy, W. Cherry and W. Farneth, Chem. Rev., 1978, 78, 125.

11 For reviews on the photochemistry of $\beta, \gamma$-unsaturated enones: (a) M. G. Banwell and D. J.-Y. D. Bon, in Molecular Rearrangements in Organic Synthesis, ed. C. M. Rojas, Wiley, Hoboken, NJ, 2015, ch. 9, p. 261; (b) T. Tsuno, in Handbook of Synthetic Photochemistry, ed. A. Albiniand M. Fagnoni, Wiley-VCH, Weinheim, 2010, p. 95; (c) D. Armesto, M. J. Ortiz and A. R. Agarrabeitia, in CRC Handbook of Organic Photochemistry and Photobiology, ed. W. Horspool and F. Lenci, CRC Press, Boca Raton, 2nd edn, 2004, pp. 77-1; (d) H. E. Zimmerman and D. Armesto, Chem. Rev., 1996, 96, 3065; (e) K. N. Houk, Chem. Rev., 1976, 76, 1.

12 Reviews: (a) R. Remy and C. G. Bochet, Chem. Rev., 2016, 116, 9816; (b) N. Hoffmann, Photochem. Photobiol. Sci., 2012, 11, 1613; (c) U. Streit and C. G. Bochet, Beilstein J. Org. Chem., 2011, 7, 525; (d) U. Streit and C. G. Bochet, Chimia, 2008, 62, 962; (e) J. Mattay, Angew. Chem., Int. Ed., 2007, 46, 663; (f) N. Hoffmann, Synthesis, 2004, 481; (g) J. Cornelisse and R. de Haan, in Molecular and Supramolecular Photochemistry, ed. V. Ramamurthy and K. S. Schanze, Dekker, New York, 2001, vol. 8, p. 1; (h) P. J. Wagner, Acc. Chem. Res., 2001, 34, 1.

13 For some recent contributions to dearomatization by arene photocycloaddition, see: (a) U. Streit, F. Birbaum, A. Quattropani and C. G. Bochet, J. Org. Chem., 2013, 78, 6890; (b) A. Zech and T. Bach, J. Org. Chem., 2018, 83, 3069; (c) M. J. James, J. L. Schwarz, F. Strieth-Kalthoff, B. Wibbeling and F. Glorius, J. Am. Chem. Soc., 2018, 140, 8624; (d) T. W. Bingham, L. W. Hernandez, D. G. Olson, R. L. Svec, P. J. Hergenrother and D. Sarlah, J. Am. Chem. Soc., 2019, 141, 657.

14 For a para photocycloadditon to 1-naphthaldehyde (1), see: D. Döpp and H. R. Memarian, Chem. Ber., 1990, 123, 315.

15 (a) M. Yamashita, J. Onozuka, G.-i. Tsuchihashi and K. Ogura, Tetrahedron Lett., 1983, 24, 79; (b) K. Ishihara and K. Nakano, J. Am. Chem. Soc., 2007, 129, 8930; (c) À. Gutiérrez-Bonet, A. Flores-Gaspar and R. Martin, J. Am. Chem. Soc., 2013, 135, 12576.

16 For reviews on rearrangement of carbocations by a 1,2-shift see: (a) X.-M. Zhang, Y.-Q. Tu, F.-M. Zhang, Z.-H. Chen and S.-H. Wang, Chem. Soc. Rev., 2017, 46, 2272; (b) R. R. Naredla and D. A. Klumpp, Chem. Rev., 2013, 113, 6905; (c) V. G. Shubin, Top. Curr. Chem., 1984, 117, 267.

17 J. J. McCullough, R. C. Miller and W.-S. Wu, Can. J. Chem., 1977, 55, 2909.

18 For seminal studies on the influence of Lewis acids on the photochemistry of carbonyl compounds, see: (a) F. D. Lewis and S. V. Barancyk, J. Am. Chem. Soc., 1989, 111, 8653; (b) F. D. Lewis, S. V. Barancyk and E. L. Burch, J. Am. Chem. Soc., 1992, 114, 3866.

19 (a) R. F. Childs, D. L. Mulholland and A. Nixon, Can. J. Chem., 1982, 60, 801; (b) P. Laszlo and M. Teston, J. Am. Chem. Soc., 1990, 112, 8750.

20 (a) W. L. Dilling, T. E. Tabor, F. P. Boer and P. P. North, J. Am. Chem. Soc., 1970, 92, 1399; (b) N. P. Peet, R. L. Cargill and D. F. Bushey, J. Org. Chem., 1973, 38, 1218; (c) N. C. Yang, M. Kimura and W. Eisenhardt, J. Am. Chem. Soc., 1973, 95, 5058; (d) J. F. D. Kelly, J. M. Kelly and T. B. H. McMurry, J. Chem. Soc., Perkin Trans. 2, 1999, 1933; (e) R. Brimioulle, A. Bauer and T. Bach, J. Am. Chem. Soc., 2015, 137, 5170.

21 (a) J. Halpern, Science, 1982, 217, 401; (b) J. M. Brown, Chem. Soc. Rev., 1993, 22, 25. 